\title{
Platelets
}

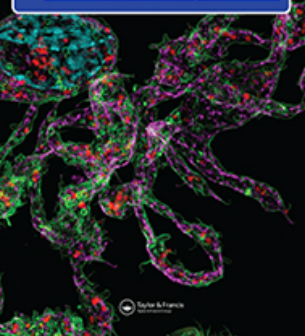

\section{The use of platelet-rich plasma to treat chronic tendinopathies: A technical analysis}

\author{
Jean-François Kaux \& Thibault Emonds-Alt
}

To cite this article: Jean-François Kaux \& Thibault Emonds-Alt (2018) The use of plateletrich plasma to treat chronic tendinopathies: A technical analysis, Platelets, 29:3, 213-227, DOI: 10.1080/09537104.2017.1336211

To link to this article: https://doi.org/10.1080/09537104.2017.1336211

\section{册朋 Published online: 31 Jul 2017.}

Submit your article to this journal $\pi$

Џ Article views: 88

Q View related articles $₫$

View Crossmark data ¿ 


\title{
The use of platelet-rich plasma to treat chronic tendinopathies: A technical analysis
}

\author{
Jean-François Kaux \& Thibault Emonds-Alt \\ Physical Medicine, Rehabilitation and Sports Traumatology Department, FIFA Medical Centre of Excellence, University and University Hospital of Liège, \\ Liège, Belgium
}

\begin{abstract}
Platelet-rich plasma (PRP) is blood plasma with a high concentration of autologous platelets which constitute an immense reservoir of growth factors. The clinical use of PRP is widespread in various medical applications.

Although highly popular with athletes, the use of PRP for the treatment of tendinopathies remains scientifically controversial, particularly due to the diversity of products that go by the name of "PRP." To optimize its use, it is important to look at the various stages of obtaining PRP.

In this literature review, we take a closer look at eight parameters which may influence the quality of PRP: 1) anticoagulants used to preserve the best platelet function, 2) the speed of centrifugation used to extract the platelets, 3) the platelet concentrations obtained, 4) the impact of the concentration of red and while blood cells on PRP actions, 5) platelet activators encouraging platelet degranulation and, hence, the release of growth factors, and 6) the use or nonuse of local anesthetics when carrying out infiltration. In addition to these parameters, it may be interesting to analyze other variables such as 7) the use of ultrasound guidance during the injection with a view to determining the influence they have on potential recovery.
\end{abstract}

\author{
Keywords \\ Collection, optimization, platelet-rich plasma, \\ PRP, standardization, tendinopathies
}

\section{History}

Received 21 January 2017

Revised 23 April 2017

Accepted 15 May 2017

Published online 1 August 2017

\section{Introduction}

Platelet-rich plasma (PRP) consists of blood plasma with a high concentration of autologous platelets which constitute an immense reservoir for growth factors [1,2], as PDGF (PlateletDerived Growth Factor), IGF-1 (Insuline-Like Growth Factor), TGF- $\beta$ (Transforming Growth Factor), EGF (Epidermal Growth Factor), VEGF (Vascular Endothelial Growth Factor), etc. These are essential for the initiation and stimulation of the healing mechanism and the synthesis of collagen among other actions $[3,4]$. The clinical use of PRP is widespread in various areas such as maxillo-facial surgery, sports traumatology, orthopedic surgery, and dermatology [5-7].

The conservative treatment of tendinopathies is difficult, and pain remains often rebel to classic treatments [8,9]. This is why new treatments, including PRP, are currently being assessed. Although highly popular with athletes, however, its use remains scientifically controversial [10-12], particularly of products and kits available in the market as PRP and also due to different methodologies and lack of standardization to obtain PRP [1315]. To optimize its use, it is important to take a look at the various stages of obtaining PRP [16].

We decided to carry out a literature review and, more specifically, to analyze eight parameters which can influence the quality of PRP: 1) anticoagulants used to preserve the best platelet

Correspondence: Jean-François KAUX, Physical Medicine and Sport Traumatology, University Hospital of Liège, Avenue de l'Hôpital, B35, 4000 Liège, Belgium, E-mail: jfkaux@ @hu.ulg.ac.be function, 2) the speed of centrifugation used to extract the platelets, 3) the platelet concentrations obtained, 4) the presence of leukocytes and erythrocytes in the PRP, 5) platelet activators encouraging platelet degranulation and, hence, the release of growth factors, and 6) the use or nonuse of local anesthetics when carrying out infiltration. In addition to these parameters, it may be interesting to analyze other variables such as 7) the use of ultrasound guidance during the injection with a view to determining the influence they have on potential recovery.

\section{Material and methods}

A search for articles was conducted in the Pubmed and Pedro databases. The results were obtained by using the following key words and combinations of these key words: PRP, platelet-rich plasma, injection, treatment, tennis elbow, greater trochanteric pain syndrome, jumper's knee, Achilles tendinopathy, plantar fasciitis, anticoagulant, sodium chloride, local anesthetic, and centrifugation speed.

\section{Results}

The studies are given in chronological order in the form of summary tables according to the type of tendinopathy treated (Tables I-IV) [17-69].

\section{Anticoagulant}

The choice of anticoagulant capable of preserving the greatest platelet integrity and functionality is an important factor. In 


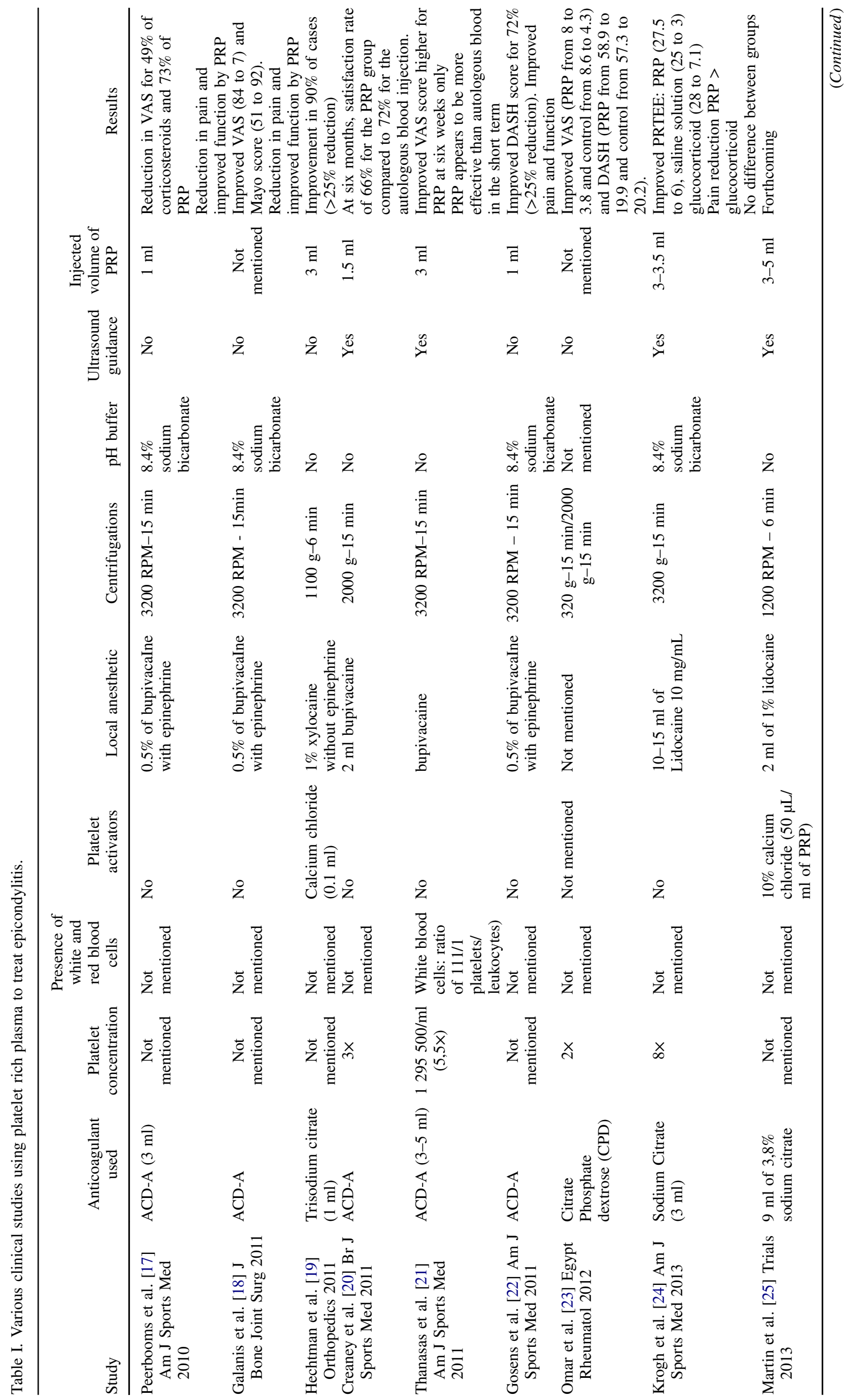




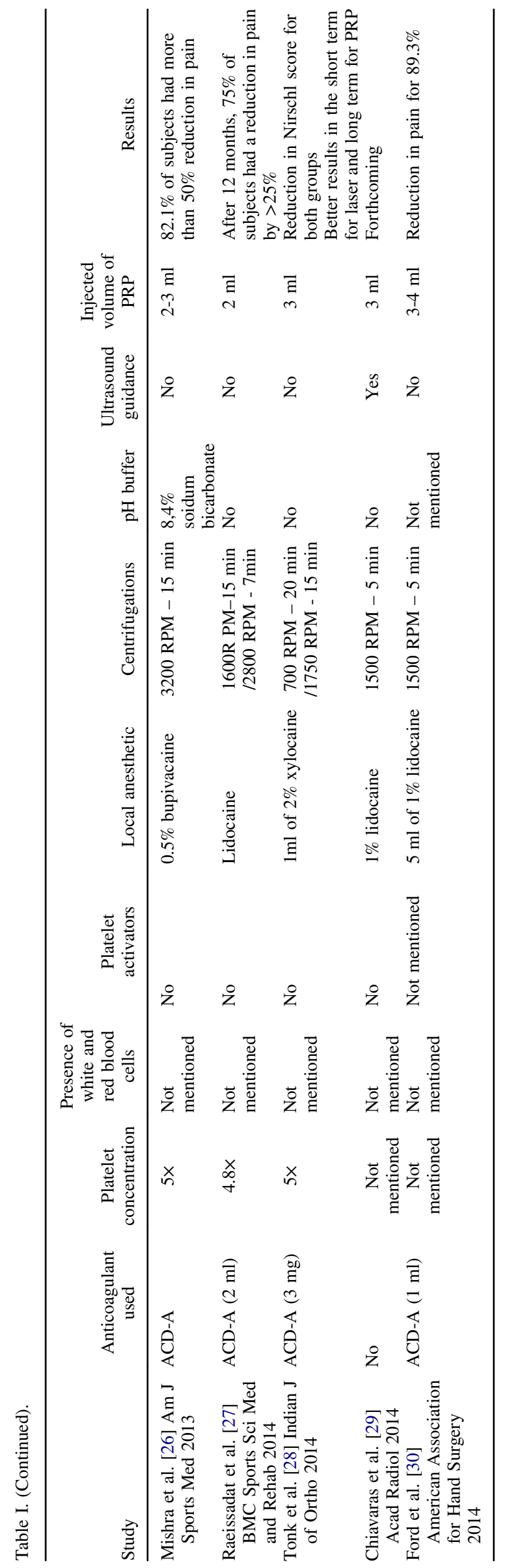




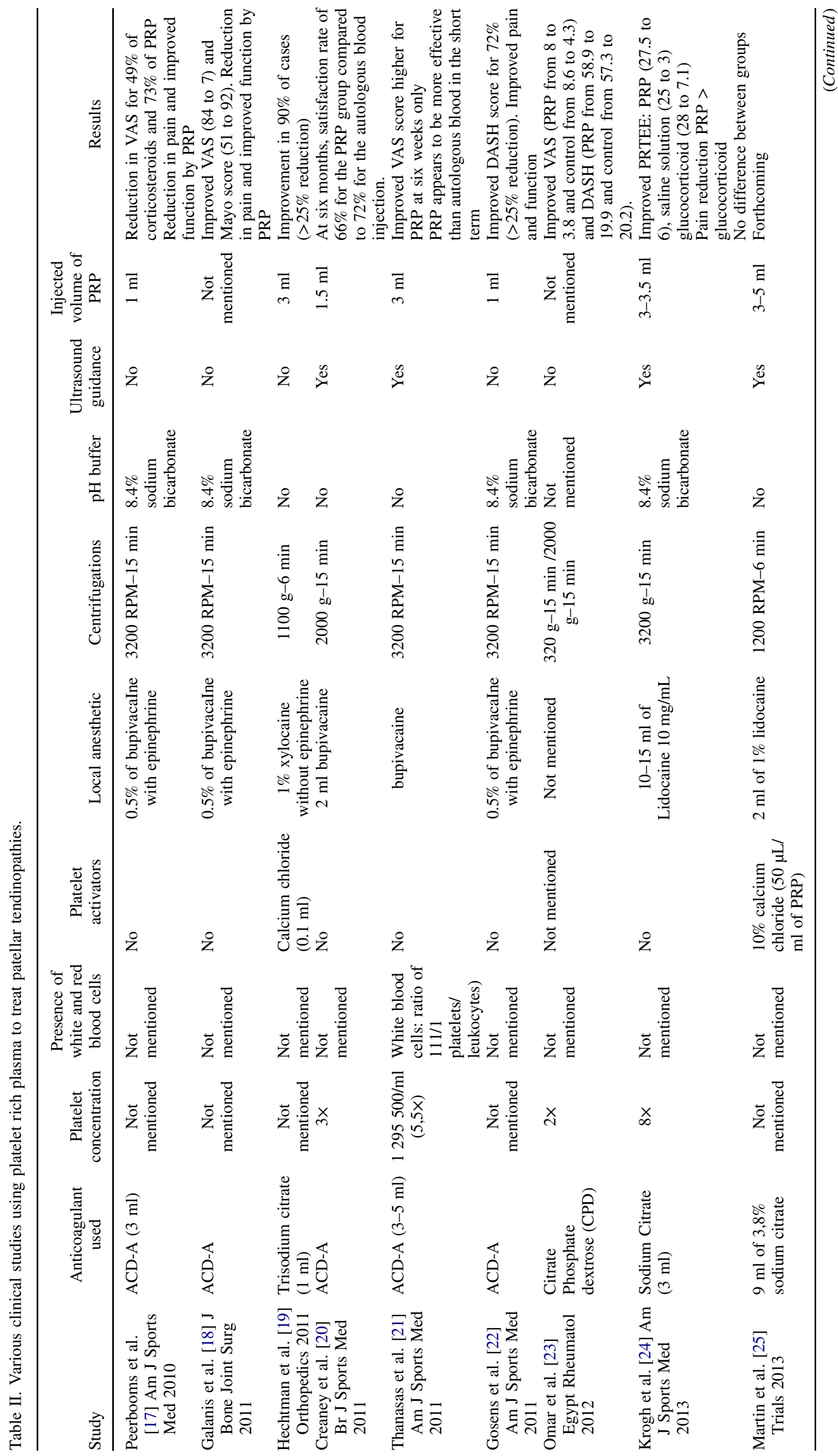




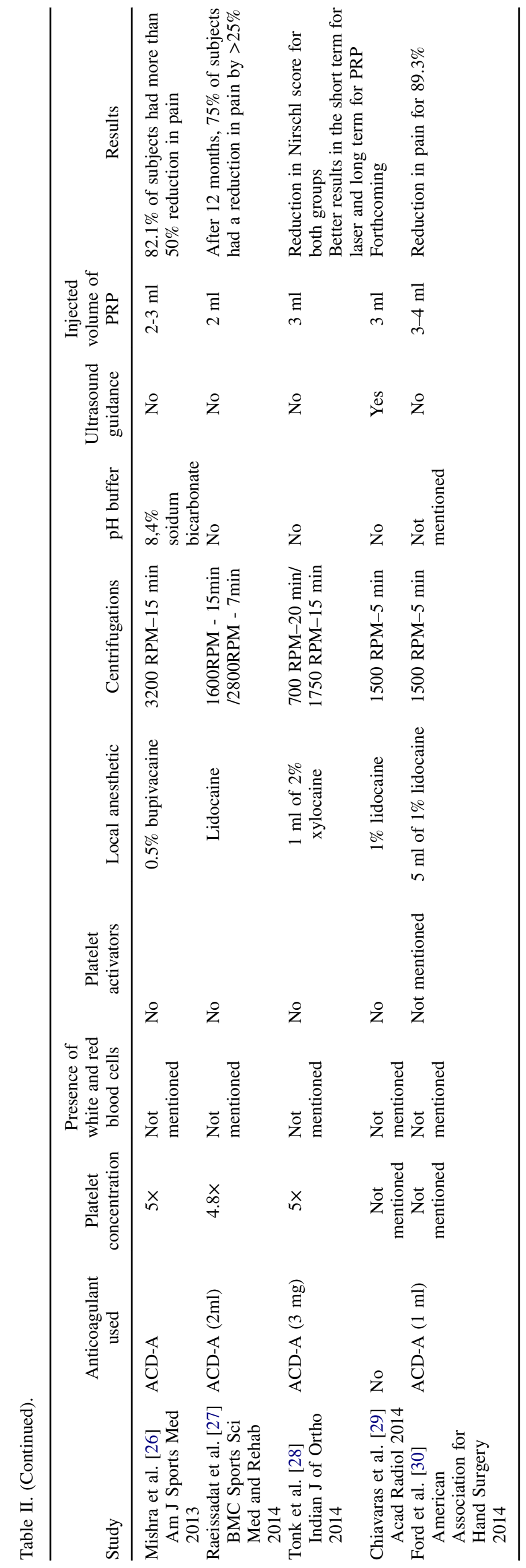




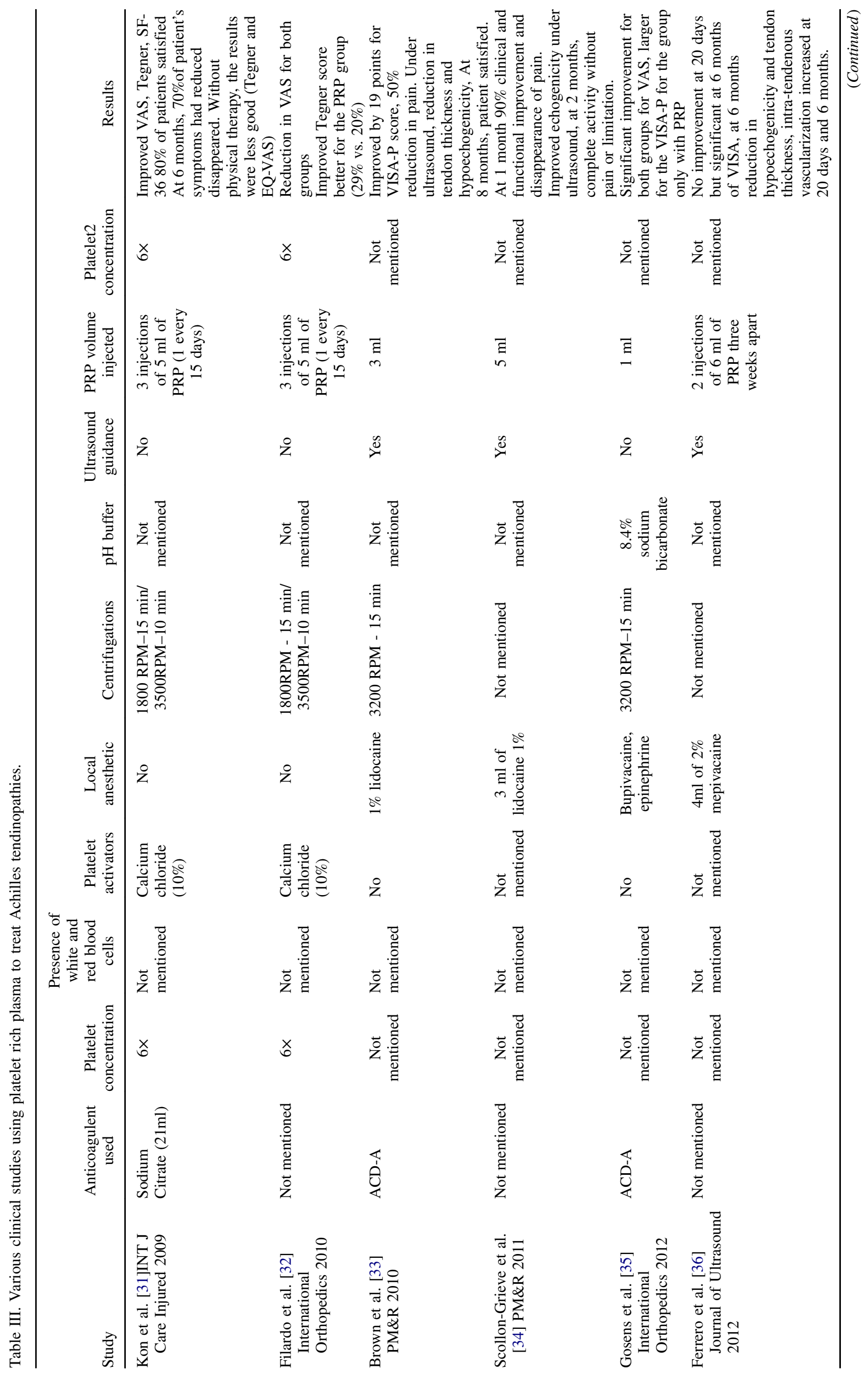




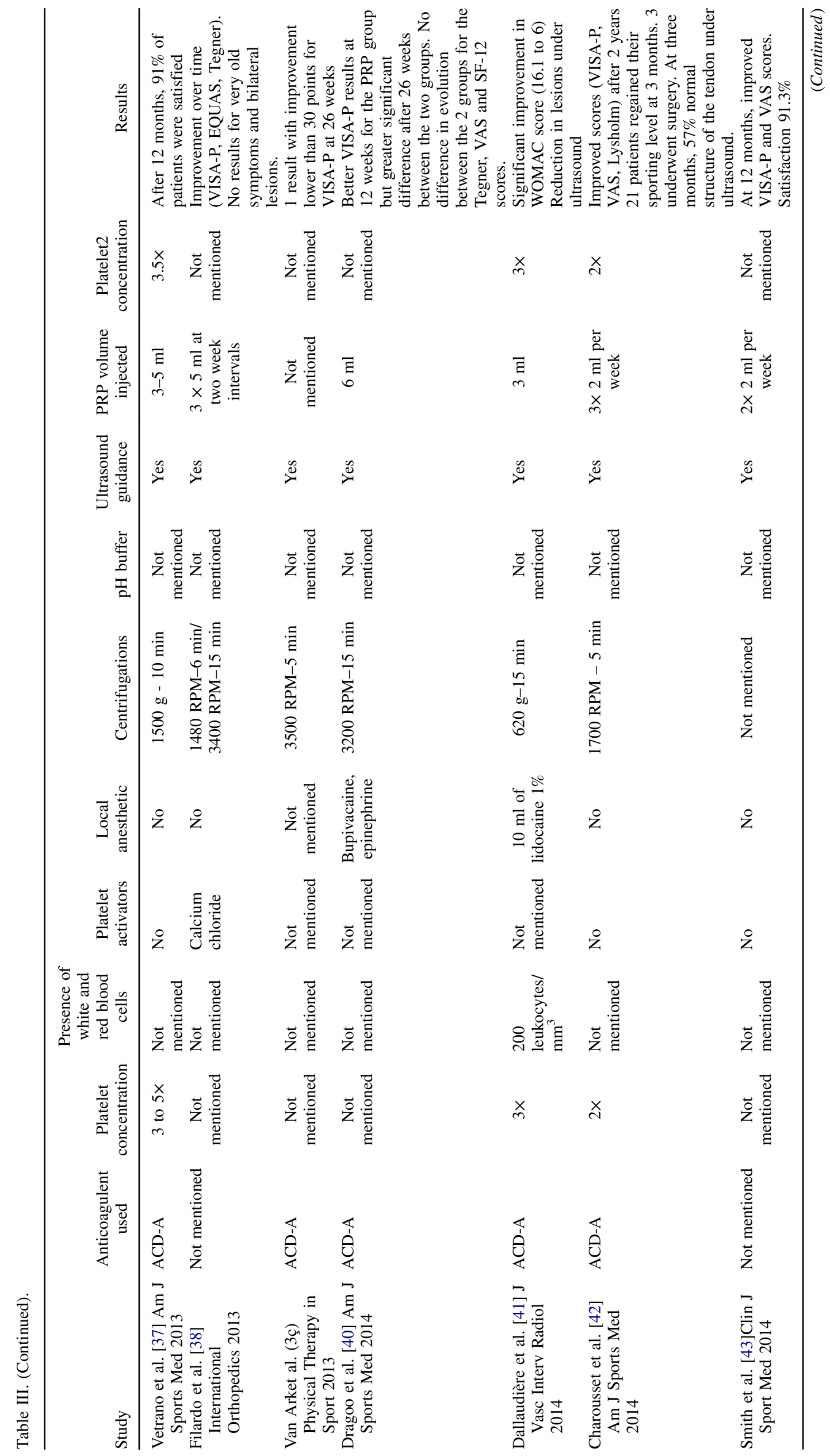




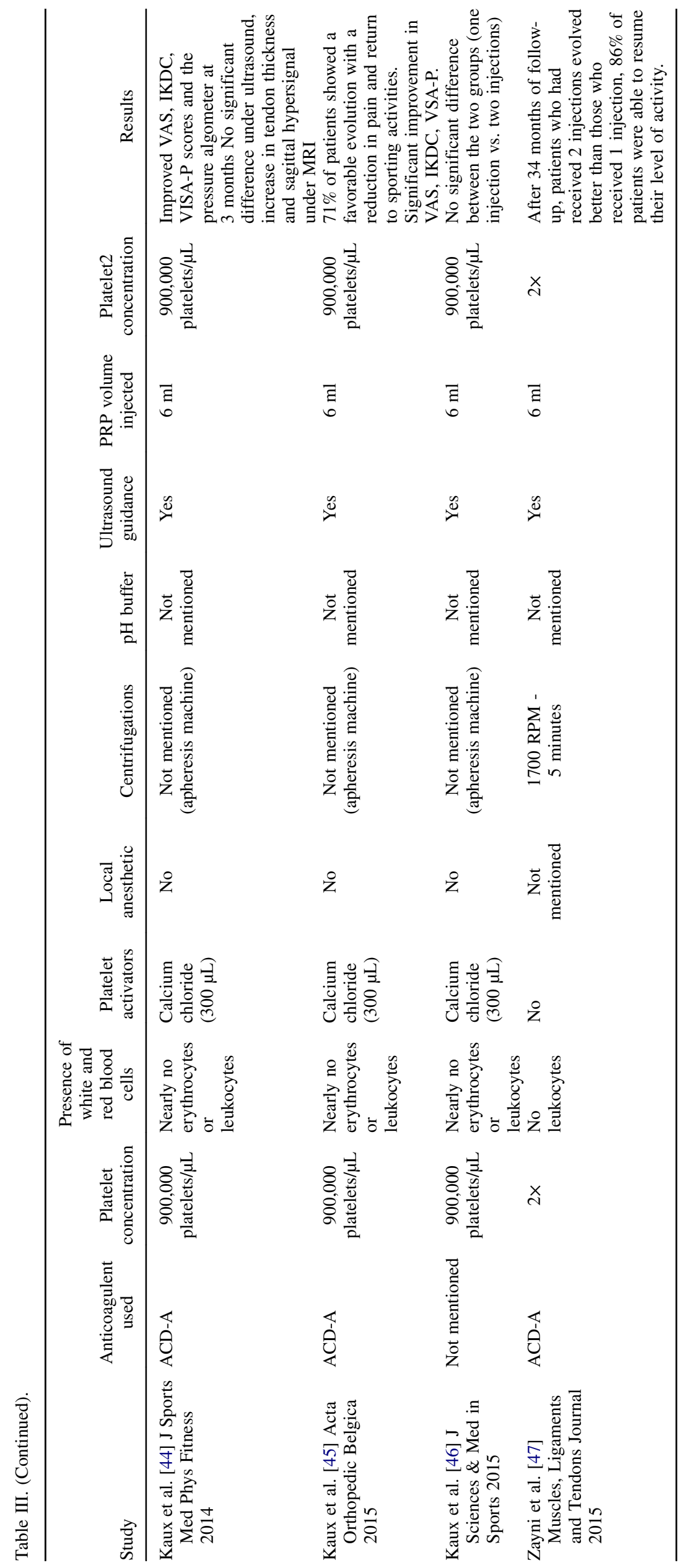




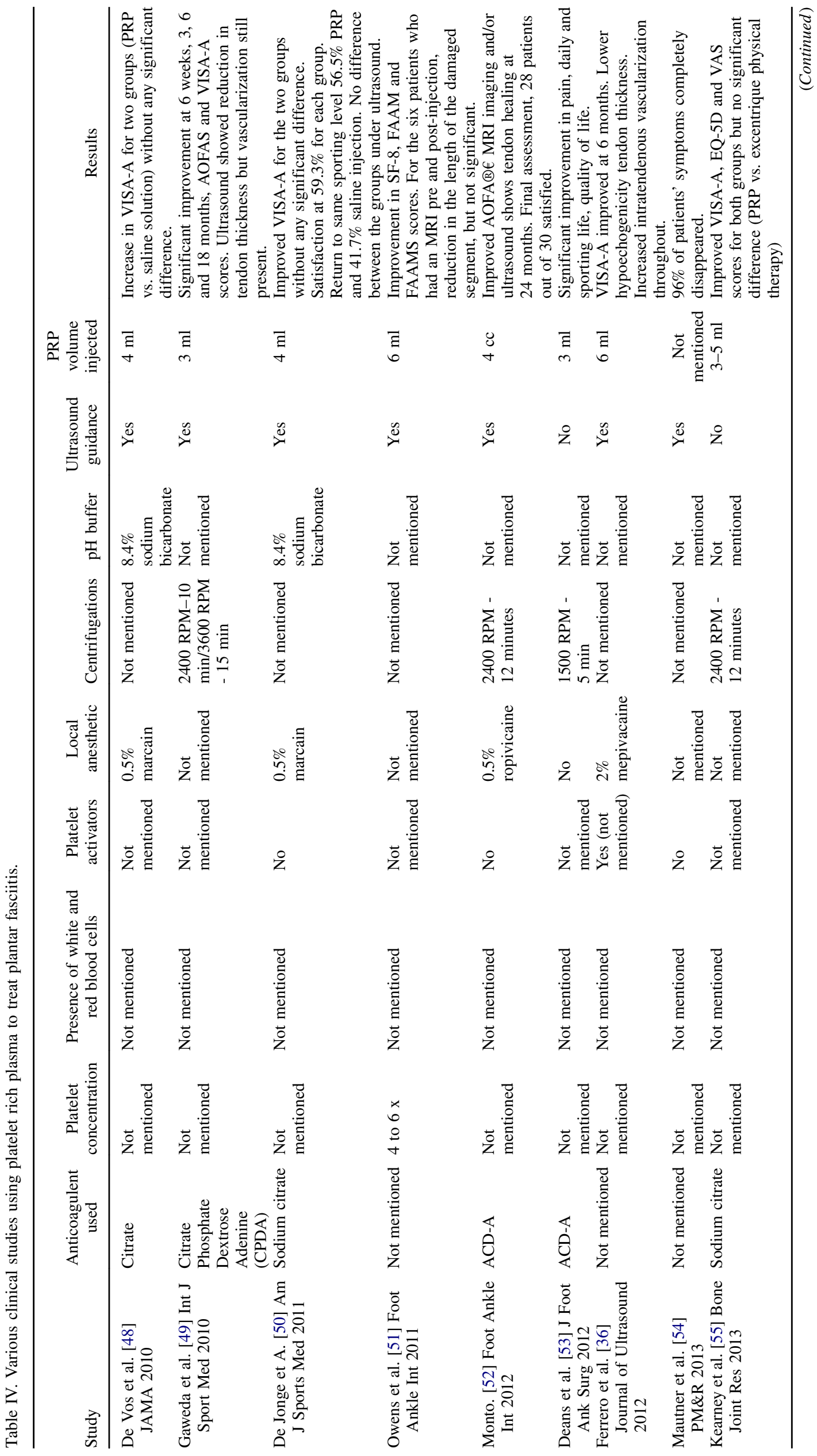




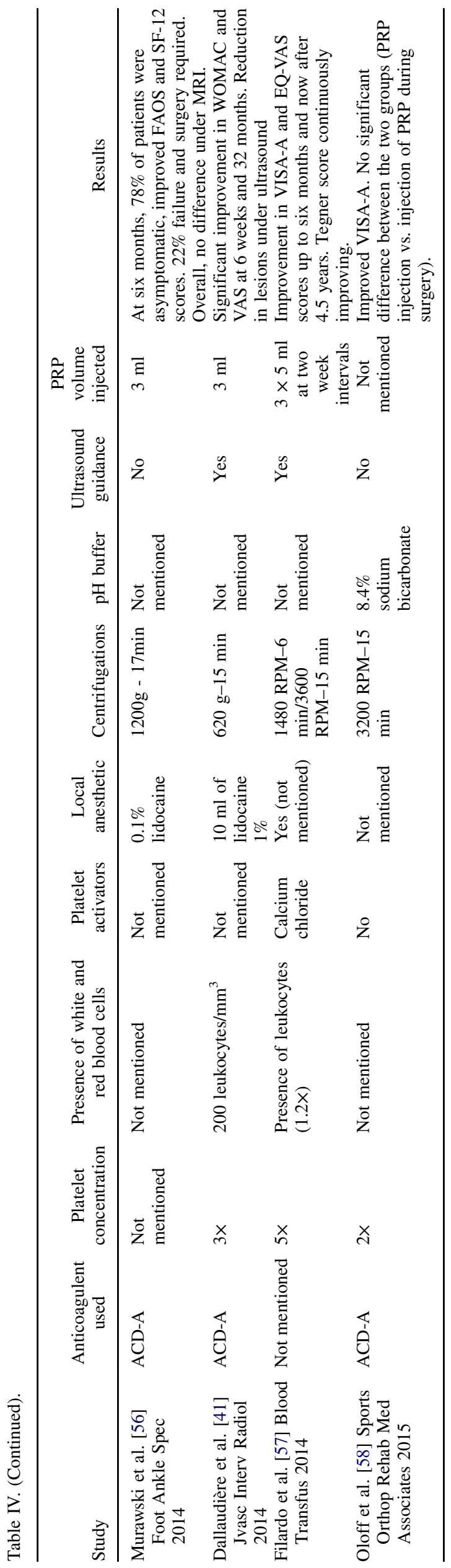


terms of the type of anticoagulant, most authors agree on the nonuse of EDTA (ethylene diamine tetra-acetic acid) which may damage the platelet membrane. Hence, we will focus on the use of anticoagulants containing citrate-dextrose or sodium citrate [70].

Acid-citrate-dextrose (ACD) is an anticoagulant used by blood banks to store viable platelets for transfusion. ACD can maintain platelet viability for six hours [71]. In a study analyzing the effects of anticoagulants on PRP quality, Lei et al. [72] highlighted that ACD maintains the integrity of the structure of platelets in the PRP for up to 12 hours. However, when heparin sodium and sodium citrate are used, half of the platelets begin to rupture in the first hours. The positive effect of ACD on maintaining platelet viability may be due to glucose and the low citrate concentration [73]. One alternative to ACD-A is citrate phosphate dextrose-adenine (CPDA). This anticoagulant is similar, but is $10 \%$ less effective in terms of maintaining platelet viability [74].

\section{Centrifugation speed}

Several factors may influence the integrity of platelets as well as the composition and effectiveness of PRP. These include the number of revolutions per minute (RPM), centrifugal acceleration and duration of centrifugation, and angular speed and distance separating the platelets from the rotor axis.

Perez et al. [75] attempted to highlight elements of the centrifugation stage required to obtain reproducible and high-quality results. Blood samples were taken from 20 healthy donors. Two stages of centrifugation were analyzed to identify the influence of centrifugal acceleration, duration, the volume treated, and the platelet gradient. They concluded that low centrifugal promoted the separation of PRP. Treating $3.5 \mathrm{ml}$ of blood at $100 \mathrm{~g}$ for 10 minutes (first centrifugation) followed by a second centrifugation at $400 \mathrm{~g}$ for 10 minutes, which had previously removed $2 / 3$ of the remaining plasma, enabled a higher rate (70-80\%) and higher concentration $(5 \mathrm{x})$ of platelets to be recovered while maintaining platelet integrity and viability. When using a larger volume $(8.5 \mathrm{ml})$, platelet recovery was lower. The authors therefore concluded that centrifugal acceleration, the duration of centrifugation, the platelet gradient prior to sampling, and the volume treated were the main elements to be retained in order to ensure a reproducible composition of PRP.

In contrast to the study by Perez et al. [75], a recent study by Arora et al. [76] showed better results with centrifugal acceleration of $440 \mathrm{~g}$ for 10 minutes. This difference may be due to the difference in the initial volume used for the preparation of PRP. There are numerous protocols in the current literature which describe the optimal conditions for centrifugation.

\section{Platelet concentration}

To date, very few studies have been carried out on the optimal dosage of platelets in PRP. Numerous researchers have, however, suggested that platelet concentration must be three to seven times higher than that found in peripheral blood (between 150,000 and 350,000 platelets $/ \mu \mathrm{L}$ ) [77,78]. Weibrich et al. [79] assessed, in vivo, the effects of different platelet concentrations on bone regeneration. He found that the use of platelet concentrate had positive effects, on the condition that the platelet concentration was approximately between 503,000 and $1,729,000$ platelets $/ \mu \mathrm{L}$ (1.5 to 4.5 times the concentration of platelets in peripheral blood). Indeed, the use of an excessively high platelet rate (6 to 12 times the concentration of platelets in peripheral blood) appeared to have an inhibitory effect on healing. Graziani et al. [78] assessed the effect of different concentrations of PRP on osteoblast and fibroblast function in vitro. The results of this study showed that PRP has a maximum effect when obtained with a platelet concentration which is 2.5 times higher than the concentration in peripheral blood. Increased concentrations lead to a reduction in the proliferation of osteoblasts and fibroblasts, suggesting a paradoxical inhibitory effect on tissue regeneration.

The large variety of platelet concentrations encountered in many studies is explained by the use of commercial kits to prepare PRP. The results of these kits vary significantly from one patient to another but also from one sample to another for the same patient $[13,14]$. Only use of an apheresis machine can obtain a constant concentration and reproducibility for each patient [80]. The donation of blood components through apheresis has become commonplace in modern blood transfusion practices. Technological progress in automated cell separators has improved the productivity and quality of platelet collection through apheresis [81]. There are a wide variety of instruments to extract platelets through apheresis, and many studies have compared different cell separators. Of those, Keklik et al. [82] compared three apheresis systems (Fenwal Amicus, Fresenius COM.TEC and Trima Accel) in terms of processing time, platelet output, efficiency, and speed of collection. The results showed that the volume of blood treated, the volume of ACD-A, and the average separation time were significantly higher with the COM.TEC system.

Altuntas et al. [83] compared two apheresis systems (Fenwal Amicus and Fresenius COM.TEC), comparing processing time, platelet output, efficiency of collection, and white cell content. The results obtained showed that both instruments collected platelets efficiently with an equal leukocyte content; however, Amicus achieved the desired platelet rate more quickly.

Moog et al. [80] demonstrated that the COM.TEC machine enabled platelet concentrates to be acquired with a lower rate of leukocytes meeting the standards in place. To do so, five centers collected 554 samples using the COM.TEC cell separator. Two cell counting studies were carried out at the start and at the end of the study to confirm a uniform count between the participating centers.

\section{The impact of the concentration of red and while blood cells on PRP actions}

The presence of red and white blood cells in the PRP may also impact upon the effectiveness of the treatment.

Indeed, the lysis of erythrocytes can cause the generation of highly reactive oxygen metabolites (also called oxygen-deviated free radicals) which can cause tissue damages and may hinder the healing process [84].

Moreover, the release of pro-inflammatory factors (cytokine and metalloproteinase) by the leukocytes may lead to deterioration of the extracellular matrix. Zhang et al. [85] published the hypothesis that PRP containing high levels of leukocytes (L-PRP) increases the concentration of catabolic cytokine and induces inflammation and apoptosis of tendon cells. This study compared the effects of L-PRP and PRP on the morphology, proliferation, and differentiation of tendon cells. The results of this study showed that L-PRP has negative effects on tendon stem cells by inhibiting their proliferation, accelerating their differentiation and inducing their apoptosis. McCarrel et al. [86] also came to the conclusion that a low concentration of leukocytes leads to a reduction in the inflammatory expression of cytokines. Another study carried out on patellar tendons in white mice by Dragoo et al. [87] compared the inflammatory effects of an injection of PRP containing high levels of leukocytes (L-PRP) to those of an injection of PRP with few leukocytes. The results showed that the L-PRP provoked a significant inflammatory response for five days after the injection. The authors observed an increased rate of 
leukocytes and mononuclear cells (macrophages and lymphocytes) in the tendons treated with L-PRP in comparison to those treated with PRP. They also noted an increase in vascularization and fibrosis of these tissues.

Pizza et al. [88] studied the effects of neutrophiles (pro-inflammatory factors) on the extracellular muscle matrix. It appeared that the neutrophiles could damage the skeletal myotubes in vitro and aggravate injuries or delay tissue regeneration in vivo.

With these observations, we recommend the use of leukocyte poor PRP (and without any erythrocytes) to avoid any local inflammatory reaction which can be painful for the patient and reduce the proliferative phase of the healing process. However, in the clinical literature in human, the results can also be good with the use of L-PRP; the disparity of the PRP used would be responsible for the variability of the results obtained. Thus, a general agreement on the preparation and the type of the PRP to use in orthopedics is still need.

\section{Platelet activator}

Activation of PRP prior to the injection is another parameter which requires in-depth examination. Platelet activation leads to the degranulation of alpha granules. The release of numerous proteins and growth factors (including PDGF, TGF- $\beta$, VEGF, and IGF) stimulates the healing process [10,89]. Platelets may be activated exogenously by thrombin, calcium chloride, or as the result of mechanical trauma. Denatured collagen is a natural PRP activator, and when used within soft tissue, exogenous activation is not always necessary [90,91].

Once the PRP is activated, a fibrin network starts to form, solidifying plasma and creating a fibrin clot or membrane which contributes toward tissue healing. According to Weibrich et al. [92], no significant changes in platelet or growth factor concentration are observed according on the patient's age or sex. Several studies, however, report that the hematocrit and total platelet level influence the platelet concentration of PRP [92,93]. Indeed, the higher the hematocrit and platelet levels are, the greater the platelet concentration will be.

A study by Martineau et al. [94] showed that PRP activation with a high concentration of calcium and thrombin leads to an immediate and significant increase in the release of growth factors.

\section{Local anesthetic}

Although intratendon injections are painful, the use of a local anesthetic is not recommended as it may compromise the therapeutic potential of PRP: The anesthetic may reduce local $\mathrm{pH}$, leading to an inhibition, reduction, or absence of platelet degranulation [16]. This hypothesis has been confirmed by Bausset et al. [95] who showed that the association formed by a local anesthetic (lidocaine, ropivacaine) and PRP injections in vitro leads to a significant reduction in platelet functionality, in particular platelet aggregation. He therefore recommends using smaller needles. Carofino et al. [96] tried to identify the effects of the association formed by an anesthetic (lidocaine, bupivacaine) or a corticosteroid (methylprednisolone) and PRP on human tenocytes in vitro. He came to the conclusion that adding one or the other to the PRP resulted in a significant reduction in tenocyte proliferation and cell viability.

\section{Ultrasound guidance}

Many studies do not use ultrasound guidance. In such cases, the area to be treated is identified by palpation, followed by a series of injections in order to obtain complete coverage of the site [97]. The growing use of ultrasound to guide injections enables the
PRP injection into the pathological tendon to be visualized. The basic principle of PRP is to inject a high concentration of active proteins and growth factors to the injury site. It would, therefore, appear relevant to identify the extent to which the product effectively remains at the injection site and what quantity is dispersed into the surrounding tissue. It has, nonetheless, been demonstrated that PRP diffused several centimeters from the injection site in the minutes following infiltration [97].

\section{Discussion}

Although there is an increasing amount of scientific proof about the benefits of PRP infiltration in the treatment of tendinopathies, there is currently no consensus as to how to obtain or use it. This may partly explain the disparity of results obtained in the literature. Similarly, the biological parameters and risk factors for tendinopathies of patients themselves may possibly influence the results of this treatment even if, to date, this has not yet been demonstrated [98].

Analysis of these studies (Tables I-IV) shows that a majority use ACD-A as an anticoagulant during sampling. By comparing the results of studies using ACD-A and sodium citrate (seven studies), we were able to highlight the greater effectiveness of ACD-A. However, the small number of studies using sodium citrate does not allow us to confirm this hypothesis.

A platelet activator is only used in a few studies (eight studies). Of those, calcium chloride is the main product used. Each study using this platelet activator presents positive results. However, the best results have been obtained in studies which use no platelet activator.

It is, however, important to note that the results are obtained by adding a range of variables which are not reproducible from one study to the next (anticoagulant, platelet activator, local anesthetic, speed of centrifugation, $\mathrm{pH}$ buffer, ultrasound guidance, volume of PRP injected). As such, it is impossible to draw conclusions about the greater effectiveness of ACD-A and the real value of using a platelet activator.

In terms of the speed of centrifugation, analysis of all these studies appears to confirm the existence of a great number of protocols in the literature. It is difficult to draw any conclusions when these different variables are unknown (volume of initial sample, equipment used to obtain the PRP).

Currently, no studies have been carried out neither on the use of a "buffer" product to neutralize the acidity caused by the anticoagulant nor on the optimal volume of PRP to be injected.

Although it would appear inadvisable to administer a local anesthetic because the anesthetic may reduce the local $\mathrm{pH}$ and lead to the inhibition, reduction, or absence of platelet degranulation, the literature shows that the majority use a local anesthetic (32 studies out of 57). They do not, however, obtain better results than those not using a local anesthetic.

Finally, it appears to be advisable to carry out infiltration under ultrasound guidance, even if PRP diffusion is observed after injection.

This all aims to show that there is still a need for high quality studies, with standardized collection protocols and the use of PRP in the context of tendinopathies, in order to better scientifically understand the real effectiveness.

\section{Declaration of interest}

The authors report no conflicts of interest

\section{References}

1. Kaux J-F, Degrave N, Crielaard J-M. Platelet rich plasma: traitement des tendinopathies chroniques? Revue de la littérature. J Traumatol Sport 2007;24(2):99-102. 
2. Kaux JF, Croisier JL, Forthomme B, Crielaard JM. Nouveaux traitements conservateurs des tendinopathies chroniques. Rev Med Liege 2015;70(10):507-510.

3. Mejia HA, Bradley JP. The effects of platelet-rich plasma on muscle: basic science and clinical application. YOTSM. Elsevier Inc. 2011;19(3):149-153.

4. Kaux JF, Drion P, Croisier JL, Crielaard JM. Tendinopathies and platelet-rich plasma (PRP): from pre-clinical experiments to therapeutic use. J Stem Cells Regener Med 2015;11(1):P7-P17.

5. Foster TE, Puskas BL, Mandelbaum BR, Gerhardt MB, Rodeo SA. Platelet-rich plasma: from basic science to clinical applications. Am J Sport Med 2009;37(11):2259-2272.

6. Marx RE, Carlson ER, Eichstaedt RM, Schimmele SR, Strauss JE, Georgeff KR. Platelet-rich plasma: growth factor enhancement for bone grafts. Oral Surg Oral Med Oral Pathol Oral Radiol Endodontol 1998;85(6):638-646.

7. Rožman P, Bolta Z. Use of platelet growth factors in treating wounds and soft-tissue injuries. Acta Dermatovenerologica Alpina, Pannonica Adriat 2007;16(4):156-165.

8. Kaux J-F, Crielaard J-M. Tendon et tendinopathie. J Traumatol Sport 2014;31(4):235-240.

9. Sancerne A, Kaux JF. Revue épidémiologique des tendinopathies les plus fréquentes. J Traumatol Sport 2015;32(4):223-228.

10. Smets F, Croisier J-L, Forthomme B, Crielaard J-M, Kaux J-F. Applications cliniques du plasma riche en plaquettes (PRP) dans les lésions tendineuses: revue de la littérature. Sci Sports 2012;27 (3):141-153.

11. Kaux J-F, Crielaard J-M. Tendinopathies and platelet-rich plasma: clinical applications. A review of the literature I [Tendinopathies et plasma riche en plaquettes (PRP) : Applications cliniques. Revue de la littérature]. J Traumatol Sport 2012;29(3):174-178.

12. Kaux J-F, Drion P, Croisier J-L, Crielaard J-M. Plasma riche en plaquettes pour le traitement de lésions tendineuses. J Readaptation Med 2015;35(3):333, 181-191.

13. Kaux J-F, Le Goff C, Renouf J, Gothot A, Crielaard J-M, et al Comparison of the platelet concentrations obtained in platelet-rich plasma (PRP) between the GPS ${ }^{\mathrm{TM}}$ II and GPS ${ }^{\mathrm{TM}}$ III systems. Pathol Biol 2011;59(5):275-277.

14. Kaux J-F, Le Goff C, Seidel L, Albert A, Crielaard J-M, et al. Étude comparative de cinq techniques de préparation plaquettaire (plateletrich plasma). Pathol Biol 2011;59(3):157-160.

15. Marques LF, Stessuk T, Camargo IC, Sabeh Junior N, Dos Santos L, Ribeiro-Paes JT. Platelet-rich plasma (PRP): methodological aspects and clinical applications. Platelets 2014;26(2):101-113.

16. Kaux J-F, Bouvard M, Lecut C, Sanchez M, Crielaard J-M, et al. Reflections about the optimisation of the treatment of tendinopathies with PRP. Muscles, Ligaments and Tendons Journal 2015;5 (1): $1-4$.

17. Peerbooms JC, Van Laar W, Faber F, Schuller HM, Van Der Hoeven $\mathrm{H}$, Gosens T. Use of platelet rich plasma to treat plantar fasciitis: design of a multi centre randomized controlled trial. BMC Musculoskelet Disord 2010;11:69.

18. Galanis V, Monga F, Nalmpantis N, Diamantidus E, Panagiotidis D, Mitsitskas T. The use of platelet-rich plasma in severe chronic lateral epicondylitis of the elbow. J Bone Jt Surg Br 2011;93:15123.

19. Hechtman KS, Uribe JW, Botto-vanDemden A, Kiebzak GM. Platelet-rich plasma injection reduces pain in patients with recalcitrant epicondylitis. Orthopedics 2011;34(2):92.

20. Creaney L, Wallace A, Curtis M, Connell D. Growth factor-based therapies provide additional benefit beyond physical therapy in resistant elbow tendinopathy: a prospective, single-blind, randomised trial of autologous blood injections versus platelet-rich plasma injections. Br J Sports Med 2011;45(12):966-971.

21. Thanasas C, Papadimitriou G, Charalambidis C, Paraskevopoulos I, Papanikolaou A. platelet-rich plasma versus autologous whole blood for the treatment of chronic lateral elbow epicondylitis: a randomized controlled clinical trial. Am J Sports Med 2011;39(10):2130 2134.

22. Gosens T, Peerbooms JC, Van Laar W, Den Oudsten BL. Ongoing positive effect of platelet-rich plasma versus corticosteroid injection in lateral epicondylitis. Am J Sports Med 2011;39 (6): $1200-1208$.

23. Omar AS, Ibrahim ME, Ahmed AS, Said M, Author A, et al. Local injection of autologous platelet rich plasma and corticosteroid in treatment of lateral epicondylitis and plantar fasciitis: randomized clinical trial. Egypt Rheumatol Egypt Soc Jt Dis Arthritis 2012;34(2):43-49.

24. Krogh TP, Fredberg U, Stengaard-Pedersen K, Christensen R, Jensen P, Ellingsen T. Treatment of lateral epicondylitis with platelet-rich plasma, glucocorticoid, or saline: a randomized, doubleblind, placebo-controlled trial. Am J Sports Med 2013;41(3):625635.

25. Martin JI, Merino J, Atilano L, Areizaga LM, Gomez-Fernandez MC, Burgos-Alonso N, et al. Platelet-rich plasma (PRP) in chronic epicondylitis: study protocol for a randomized controlled trial. Trials 2013;14:410

26. Mishra AK, Skrepnik NV, Edwards SG, Jones GL, Sampson S, Vermillion D, et al. Platelet-rich plasma significantly improves clinical outcomes in patients with chronic tennis elbow: a doubleblind, prospective, multicenter, controlled trial of 230 patients. Am J Sports Med 2014;42(2):463-471.

27. Raeissadat SA, Rayegani SM, Hassanabadi H, Rahimi R, Sedighipour L, Rostami K. Is Platelet-rich plasma superior to whole blood in the management of chronic tennis elbow: one year randomized clinical trial. BMC Sports Sci Med Rehabil 2014;6 (1):12.

28. Tonk G, Kumar A, Gupta A. Platelet rich plasma versus laser therapy in lateral epicondylitis of elbow. Indian J Orthop 2014;48 (4):390-392.

29. Chiavaras MM, Jacobson J, Carlos R, Maida E, Bentley T, Simunovic N, et al. IMpact of platelet rich plasma over alternative therapies in patients with lateral epicondylitis (IMPROVE): protocol for a multicenter randomized controlled study: a multicenter, randomized trial comparing autologous platelet-rich plasma, autologous whole. Acad Radiol. Elsevier Ltd. 2014;21(9):1144-1155.

30. Ford RD, Schmitt WP, Lineberry K, Luce P. A retrospective comparison of the management of recalcitrant lateral elbow tendinosis: platelet-rich plasma injections versus surgery. Hand 2014;285-291.

31. Kon E, Filardo G, Delcogliano M, Presti ML, Russo A, Bondi A, et al. Platelet-rich plasma: new clinical application. Injury 2009;40 (6):598-603.

32. Filardo G, Kon E, Della Villa S, Vincentelli F, Fornasari PM, Marcacci M. Use of platelet rich plasma for the treatment of refractory jumper's knee. Int Orthop 2010;34(6):909-915.

33. Brown J, Sivan M. Ultrasound-guided Platelet-rich plasma injection for chronic patellar tendinopathy: a case report. PM\&R. Elsevier Inc. 2010;2(10):969-972.

34. Scollon-Grieve KL, Malanga GA. Platelet-rich plasma injection for partial patellar tendon tear in a high school athlete: a case presentation. PM\&R. Elsevier Inc. 2011;3(4):391-395.

35. Gosens T, Den Oudsten BL, Fievez E, Van'T Spijker P, Fievez A. Pain and activity levels before and after platelet-rich plasma injection treatment of patellar tendinopathy: a prospective cohort study and the influence of previous treatments. Int Orthop 2012;36(9):1941-1946.

36. Ferrero G, Fabbro E, Orlandi D, Martini C, Lacelli F, Serafini G, et al. Ultrasound-guided injection of platelet-rich plasma in chronic Achilles and patellar tendinopathy. J Ultrasound. Elsevier Srl. 2012;15(4):260 266.

37. Vetrano M, Castorina A, Vulpiani MC, Baldini R, Pavan A, Ferretti A. Platelet-rich plasma versus focused shock waves in the treatment of jumper's knee in athletes. Am J Sports Med 2013;41(4):795-803.

38. Filardo G, Kon E, Di Matteo B, Pelotti P, Di Martino A, Marcacci M. Platelet-rich plasma for the treatment of patellar tendinopathy: clinical and imaging findings at medium-term follow-up. Int Orthop 2013;37 (8): $1583-1589$

39. Van Ark M, Van Den Akker-Scheek I, Meijer LTB, Zwerver J. An exercise-based physical therapy program for patients with patellar tendinopathy after platelet-rich plasma injection. Phys Ther Sport. Elsevier Ltd. 2013;14(2):124-130.

40. Dragoo JL, Wasterlain AS, Braun HJ, Nead KT. Platelet-rich plasma as a treatment for patellar tendinopathy: a double-blind, randomized controlled trial. Am J Sports Med 2014;42(3):610-618.

41. Dallaudière B, Pesquer L, Meyer P, Silvestre A, Perozziello A, Peuchant A, et al. Intratendinous injection of platelet-rich plasma under US guidance to treat tendinopathy: a long-term pilot study. J Vasc Interv Radiol. Elsevier. 2014;25(5):717-723.

42. Charousset C, Zaoui A, Bellaiche L, Bouyer B. Are multiple plateletrich plasma injections useful for treatment of chronic patellar tendinopathy in athletes? A prospective study. Am J Sports Med 2014;42 (4):906-911. 
43. Smith J, Sellon JL. Comparing PRP injections with ESWT for athletes with chronic patellar tendinopathy. Clin J Sport Med 2014;24(1):88-89.

44. Kaux J, Croisier J, Bruyère $\mathrm{O}$, Rodriguez De La Cruz $\mathrm{C}$, Forthomme B, Brabant $\mathrm{G}$, et al. One injection of platelet-rich plasma associated to a submaximal eccentric protocol to treat chronic jumper's knee. J Sports Med Phys Fitness 2015;55 (9):953-961

45. Kaux JF, Crielaard JM, Bruyère $\mathrm{O}$, Croisier JL, Forthomme B, Le Goff C. One-year follow-up of platelet-rich plasma infiltration to treat chronic proximal patellar tendinopathies. Acta Orthop Belg 2015;81(2):251-256.

46. Kaux JF, Croisier JL, Forthomme B, Le Goff C, Buhler F, Savanier $\mathrm{B}$, et al. Using platelet-rich plasma to treat jumper's knees: exploring the effect of a second closely-timed infiltration. J Sci Med Sport Sports Med Aust 2014;19(3):200-204.

47. Zayni R, Thaunat M, Fayard J-M, Hager J-P, Carrillon Y, Clechet J, et al. Platelet-rich plasma as a treatment for chronic patellar tendinopathy: comparison of a single versus two consecutive injections. Muscles Ligaments Tendons J 2015;5(2):92-98.

48. De Vos RJ, Weir A, Van Schie HTM, Bierma-Zeinstra SMA, Verhaar JAN, Weinans $\mathrm{H}$, et al. Platelet-rich plasma injection for chronic Achilles tendinopathy. JAMA 2010;303(2):144.

49. Gaweda K, Tarczynska M, Krzyzanowski W, Surgery O. Treatment of Achilles tendinopathy with PRP. Int J Sports Med. 2010;31 (8):577-583

50. De Jonge S, De Vos RJ, Weir A, Van Schie HTM, Bierma-Zeinstra SMA, Verhaar JAN, et al. One-year follow-up of platelet-rich plasma treatment in chronic Achilles tendinopathy. Am J Sports Med 2011;39(8):1623-1629.

51. Owens RF, Ginnetti J, Conti SF, Latona C. Clinical and magnetic resonance imaging outcomes following platelet rich plasma injection for chronic midsubstance Achilles tendinopathy. Foot Ankle Int 2011;32(11):1032-1039.

52. Monto RR. Platelet rich plasma treatment for chronic Achilles tendinosis. Foot Ankle Int 2012;33(5):379-385.

53. Deans VM, Miller A, Ramos J, Prospective A. Series of patients with chronic Achilles tendinopathy treated with autologous-conditioned plasma injections combined with exercise and therapeutic ultrasonography. J Foot Ankle Surg. Elsevier Ltd. 2012;51(6):706710.

54. Mautner K, Colberg RE, Malanga G, Borg-Stein JP, Harmon KG, Dharamsi AS, et al. Outcomes after ultrasound-guided platelet-rich plasma injections for chronic tendinopathy: a multicenter, retrospective review. PM\&R. Elsevier Inc. 2013;5(3):169-175.

55. Kearney RS, Parsons N, Costa ML. Achilles tendinopathy management: a pilot randomised controlled trial comparing platelet-rich plasma injection with an eccentric loading programme. Bone Joint Res 2013;2(10):227-232.

56. Murawski CD, Smyth N, Newman H, Kennedy JG. A single platelet-rich plasma injection for chronic midsubstance Achilles tendinopathy: a retrospective preliminary analysis. Foot Ankle Spec 2014;7 (5):372-376

57. Filardo G, Kon E, Di Matteo B, Di Martino A, Tesei G, Pelotti P, et al. Platelet-rich plasma injections for the treatment of refractory Achilles tendinopathy: results at 4 years. Blood Transfus 2014;12 (4):533-540.

58. Oloff L, Elmi E, Nelson J, Crain J. Pretreatment and posttreatment correlation of magnetic resonance imaging and clinical assessment. Foot Ankle Spec. 2015;8(6):490-497.

59. Scioli MW. Platelet-rich plasma injection for proximal plantar fasciitis. Tech Foot Ankle Surg 2011;10(1):7-10.

60. Aksahin E, Doğruyol D, YüKsel HY, Hapa O, Doğan Ö, Çelebi L, et al. The comparison of the eVect of corticosteroids and plateletrich plasma (PRP) for the treatment of plantar fasciitis. Arch Orthop Trauma Surg 2012;132(6):781-785.

61. Ragab EMS, Othman AMA. Platelets rich plasma for treatment of chronic plantar fasciitis. Arch Orthop Trauma Surg 2012;132 (8):1065-1070.

62. Kumar V, Millar T, Murphy PN, Clough T. The treatment of intractable plantar fasciitis with platelet-rich plasma injection. Foot. Elsevier Ltd. 2013;23(2-3):74-77.

63. Tiwari M, Bhargava R. Platelet rich plasma therapy: a comparative effective therapy with promising results in plantar fasciitis. J Clin Orthop Trauma. Elsevier Ltd. 2013;4(1):31-35.
64. Martinelli N, Marinozzi A, Carnì S, Trovato U, Bianchi A, Denaro V. Platelet-rich plasma injections for chronic plantar fasciitis. Int Orthop 2013;37(5):839-842.

65. Vijay D, Mandeep D, Chintan H, Prajyot J, Suvin S. A study to compare the efficacy of corticosteroid therapy with platelet-rich plasma therapy in recalcitrant plantar fasciitis: a preliminary report. Foot Ankle Surg Eur Foot Ankle Soc 2014;20(1):10-13.

66. Wilson JJ, Lee KS, Miller AT, Wang S. Platelet-rich plasma for the treatment of chronic plantar fasciopathy in adults: a case series. Foot Ankle Spec 2014;7(1):61-67.

67. Monto RR. Platelet-rich plasma efficacy versus corticosteroid injection treatment for chronic severe plantar fasciitis. Foot Ankle Int 2014;35(4):313-318.

68. Kim E, Lee JH. Autologous platelet-rich plasma versus dextrose prolotherapy for the treatment of chronic recalcitrant plantar fasciitis. PM\&R 2014 Feb 6(2):152-158.

69. Jain K, Murphy PN, Clough TM. Platelet rich plasma versus corticosteroid injection for plantar fasciitis: a comparative study. Foot. Elsevier Ltd. 2015;25(4):8-10.

70. Anitua E, Prado R, Sánchez M, Orive G. Platelet-rich Plasma: preparation and formulation potential of plasma rich in. YOTOR. Elsevier Inc. 2012;22(1):25-32.

71. Pignatelli P, Pulcinelli FM, Ciatti F, Pesciotti M, Ferroni P, Gazzaniga PP. Effects of storage on in vitro platelet responses: comparison of ACD and $\mathrm{Na}$ citrate anticoagulated samples. J Clin Lab Anal. 1995;9(2):138-140.

72. Lei H, Gui L, Xiao R. The effect of anticoagulants on the quality and biological efficacy of platelet-rich plasma. Clin Biochem Can Soc Clin Chem 2009;42(13-14):1452-1460.

73. Gulliksson H. Platelet storage media. Vox Sang. 2014;107(3);205-212.

74. Macey M, Azam U, Mccarthy D, Webb L, Chapman ES, Okrongly D, et al. Evaluation of the anticoagulants EDTA and citrate, theophylline, adenosine, and dipyridamole (CTAD) for assessing platelet activation on the ADVIA 120 hematology system. Clin Chem. 2002;48:891-9.

75. Perez AGM, Lana JFSD, Rodrigues AA, Luzo ACM, Belangero WD, Santana MHA. relevant aspects of centrifugation step in the preparation of platelet-rich plasma. ISRN Hematol. 2014;2014:176060.

76. Arora S, Doda V, Kotwal U, Dogra M. Quantification of platelets and platelet derived growth factors from platelet-rich-plasma (PRP) prepared at different centrifugal force $(\mathrm{g})$ and time. Transfus Apher Sci. 2016;54(1):103-110.

77. Cho JM, Lee YH, Baek RM, Lee SW. Effect of platelet-rich plasma on ultraviolet binduced skin wrinkles in nude mice. J Plast Reconstr Aesthetic Surg Elsevier Ltd 2011;64(2):e31-9. doi: 10.1016/j. bjps.2010.08.014

78. Graziani F, Ivanovski S, Cei S, Ducci F, Tonetti M, Gabriele M. The in vitro effect of different PRP concentrations on osteoblasts and fibroblasts. Clin Oral Implants Res 2006;17(2):212-219.

79. Weibrich G, Hansen T, Kleis W, Buch R, Hitzler WE. Effect of platelet concentration in platelet-rich plasma on peri-implant bone regeneration. Bone 2004;34(4):665-71.

80. Moog R, Zeiler T, Heuft HG, Stephan B, Fischer EG, Kretschmer V, et al. Collection of WBC-reduced single-donor PLT concentrates with a new blood cell separator: results of amulticenter study. Transfusion 2003;43(8):1107-1114.

81. Goodnough LT, Kuter D, McCullough J, Brecher ME. Apheresis platelets: emerging issues related to donor platelet count, apheresis platelet yield platelet transfusion dose. J Clin Apher 1998;13 (3):114-119.

82. Keklik M, Eser B, Kaynar L, Solmaz M, Ozturk A, Yay M, et al. Comparison of double dose plateletpheresis on the Fenwal Amicus, Fresenius COM.TEC and Trima Accel cell separators. Transfus Apher Sci. Elsevier Ltd. 2014;51(2):193-196.

83. Altuntas F, Sari I, Kocyigit I, Kaynar L, Hacioglu S, Ozturk A, et al. Comparison of plateletpheresis on the Fenwal Amicus and Fresenius Com. TEC cell separators. Transfus Med Hemother 2008;35 (September):368-373.

84. Scott A, Km K, Cr R, Jl C, Duronio V. What do we mean by the term "inflammation"? A contemporary basic science update for sports medicine. Br J Sports Med 2004;38(3):372-380.

85. Zhang L, Chen S, Chang P, Bao N, Yang C, Ti Y, et al. Harmful effects of leukocyte- rich platelet-rich plasma on rabbit tendon stem cells in vitro. Am J Sports Med 2016;44(8):1941-51. 
86. McCarrel TM, Minas T, Fortier L. Optimization of leukocyte concentration in plateletrich plasma for the treatment of tendinopathy. J Bone Joint Surg Am 2012;94(19):e143(1-8).

87. Dragoo JL, Braun HJ, Durham JL, Ridley B, Odegaard JI, Luong R, et al. Comparison of the acute inflammatory response of two commercial platelet-rich plasma systems in healthy Rabbit Tendons. Am J Sports Med 2012;40:1274-1281.

88. Pizza FX, McLoughlin TJ, McGregor SJ, Calomeni EP, Gunning WT. Neutrophils injure cultured skeletal myotubes. Am J Physiol Cell Physiol 2001;281(1):C335-41.

89. Grageda E. Platelet-rich plasma and bone graft materials: a review and a standardized research protocol. Implant Dent 2004;13:301309.

90. Marlovits S, Mousavi M, Gäbler C, Erdös J. A new simplified technique for producing platelet-rich plasma: a short technical note. Eur Spine J. 2004 Oct;13Suppl 1:S102-6.

91. Dhurat R. Principles and methods of preparation of platelet-rich plasma: a review and author's perspective. J Cutan Aesthet Surg. 2014;7(4):189-197.

92. Weibrich G, Kleis W, Kunz-Kostomanolakis M, Loos A, Wagner W. Correlation of platelet concentration in platelet-rich plasma to the extraction method, age, sex, and platelet count of the donor. Int J Oral Maxillo Fac Implant 2001;16(5):693-699.
93. Woodell-May J, Ridderman D, Swift M, Higgins J. Producing accurate platelet counts for platelet rich plasma: validation of a hematology analyzer and preparation techniques for counting. $\mathbf{J}$ Craniofac Surg 2005;16:749-759.

94. Martineau I, Lacoste E, Gagnon G. Effects of calcium and thrombin on growth factor release from platelet concentrates: kinetics and regulation of endothelial cell proliferation. Biomaterials 2004;25(18):4489-4502.

95. Bausset O, Magalon J, Giraudo L, Louis M, Serratrice N, Frere C, et al. Impact of local anaesthetics and needle calibres used for painless PRP injections on platelet functionality. Muscles Ligaments Tendons J. 2014;4(1):18-23.

96. Carofino B, Chowaniec DM, Mccarthy MB, Bradley JP, Delaronde $\mathrm{S}$, Beitzel K, et al. Corticosteroids and local anesthetics decrease positive effects of platelet-rich plasma: an in vitro study on human tendon cells. YJARS. Elsevier Inc. 2012;28(5):711-719.

97. Loftus ML, Endo Y, Adler RS. Retrospective analysis of postinjection ultrasound imaging after platelet-rich plasma or autologous blood: observational review of anatomic distribution of injected material. AJR Am J Roentgenol 2012 Oct 199(4):W501-W505.

98. Libertiaux V, Sancerne A, Le Goff C, Crielaard JM, Kaux JF. Are there biologic factors of good prognosis after a platelet rich plasma (PRP) injection for tendinopathies. J Exercise Sports Orthopedics 2016;3(2):1-4. 